\title{
DESENVOLVIMENTO INICIAL DO MILHO COM USO DE MICRORGANISMOS
}

Ana Clara Souto ${ }^{1}$, Guilherme Debiazi Beloni ${ }^{2}$, Virginia Helena Azevedo ${ }^{3}$, Carlos Alexandre de Moraes ${ }^{4}$, Daniela Tiago da Silva Campos ${ }^{5}$

${ }^{1}$ Graduada em Engenharia Agronômica na Universidade Federal de Mato Grosso, Cuiabá, MT-Brasil

${ }^{2}$ Graduando em Engenharia Agronômica Universidade Federal de Mato Grosso, Campus de Cuiabá, MT-Brasil

${ }^{3}$ Professora Doutora do Departamento de Fitotecnia e Fitossanidade, Cuiabá, MTBrasil

${ }^{4}$ Omnia Brasil, São Paulo-SP

${ }^{5}$ Professora Doutora do Departamento de Fitotecnia e Fitossanidade, email: (camposdts@yahoo.com.br) Cuiabá, MT-Brasil

Recebido em: 15/05/2020 - Aprovado em: 15/06/2020 - Publicado em: 30/06/2020 DOI: 10.18677/EnciBio_2020B60

\section{RESUMO}

A crescente busca por tecnologias para aumentar a produtividade das culturas tem gerado estudos e experimentos para atender essa demanda. O milho é considerado uma das principais culturas agrícolas e gera uma das maiores produtividades entre os cereais produzidos no Brasil e no mundo. Sendo assim, o presente trabalho avaliou o efeito da inoculação de microrganismos no desenvolvimento incial do milho. Os tratamentos foram: 1. Testemunha, 2. Metarhizium anisopliae IBCB 425, 3. Rhizovator (produto comercial químico e atividor da microbiota do solo), 4. M. anisopliae IBCB 425 + Rhizovator, 5. Bacstim (produto comercial à base de Bacillus $\mathrm{sp}$ ). O experimento foi conduzido em casa de vegetação, em uma mistura de solo e areia $(\mathrm{p} / \mathrm{p})$, em vasos de polietileno de $3 \mathrm{Kg}$. Todas as sementes foram inoculadas com Azospirillum brasiliense, na dose de $100 \mathrm{~mL} \mathrm{ha}^{-1}$ seguindo as recomendações dos fabricantes. Os parâmetros avaliados foram: comprimento de parte aérea, número de folhas totalmente expandidas, comprimento das últimas duas folhas expandidas, massa fresca da parte aérea e raiz, massa seca da parte aérea e raiz. Obteve-se resultados no qual o tratamento com Rhizovator proporcionou o melhor desenvolvimento inicial da cultura do milho em casa de vegetação em todos os parâmetros avaliados e o fungo $M$. anisopliae IBCB 425 não proporcionou o crescimento esperado nas plantas.

PALAVRAS-CHAVE: Bacillus sp; Metarhizium anisopliae IBCB 425; Zea mays.

\section{INITIAL DEVELOPMENT OF CORN WITH THE USE OF MICRO-ORGANISMS}

\begin{abstract}
The growing search for technologies to increase crop productivity has generated studies and experiments to understand this demand. Corn is considered one of the main agricultural crops and it generates one of the highest yields among the cereals produced in Brazil and in the world. The present work evaluated the effect of inoculation of microorganisms on the initial development of corn. The treatments were: 1. Control, 2. Metarhizium anisopliae IBCB 425, 3. Rhizovator (commercial
\end{abstract}


chemical product and soil microbiota activator), 4. M. anisopliae IBCB $425+$ Rhizovator, 5. Bacstim (commercial product based on Bacillus $\mathrm{sp}$ ). The experiment was conducted in a greenhouse, in a mixture of soil and sand (w/w), in $3 \mathrm{Kg}$ polyethylene pots. All seeds were inoculated with Azospirillum brasiliense, at a dose of $100 \mathrm{~mL}$ ha $^{-1}$ following the manufacturers' recommendations. The evaluated parameters were aerial part length, number of fully expanded leaves, length of the last two expanded leaves, fresh mass of aerial part and root, dry mass of aerial part and root. Results were obtained in which the treatment with Rhizovator provided the best initial development of the corn culture in a greenhouse in all evaluated parameters and the fungus $M$. anisopliae IBCB 425 did not provide hope growth in the plants.

KEYWORDS: Bacillus sp; Metarhizium anisopliae IBCB 425; Zea mays.

\section{INTRODUÇÃO}

A agricultura sustentável é vital para a atualidade pois oferece o potencial de atender às nossas necessidades agrícolas, algo que a agricultura convencional não se preocupou em realizar. Esse tipo de agricultura utiliza uma técnica agrícola especial, na qual os recursos ambientais podem ser totalmente utilizados e, ao mesmo tempo, garante que nenhum dano seja causado (SINGH et al., 2011).

Uma opção para aumentar a produtividade agrícola de forma natural e sustentável é a utilização de microrganismos, como bactérias e fungos promotores do crescimento vegetal. A promoção do crescimento é dependente da interação da planta com os microrganismos, podendo envolver a produção de fitormônios, controle de pragas e doenças, interação com microrganismos benéficos, como os fungos micorrízicos arbusculares, e solubilizadores de nutrientes (JUNG et al., 2012; OGGERIN et al., 2013; LIAO et al., 2014).

Esta promoção pode ser resultado de diversos mecanismos, como por exemplo, a produção de reguladores de crescimento, como auxinas, citocininas e giberelinas; estímulo à ramificação da raiz e aumento da biomassa da parte aérea e da raiz; resistência a condições adversas como seca e salinidade; solubilização de fosfatos; além de atuarem como agentes no controle biológico de patógenos. Esses e outros processos contribuem aumentando o desempenho do crescimento radicular, favorecendo a absorção de água e nutrientes (HUNGRIA, 2011).

Como exemplo tem-se o Bacillus subtilis, que promove o crescimento de plantas pela sua capacidade de solubilização de nutrientes, síntese de fitormônios além da melhoria nas condições do solo que acabam por influenciar na taxa de germinação e crescimento das plantas, bem como apresentam uma boa viabilidade no mercado devido a produção de metabólitos secundários que auxiliam no controle de diversos patógenos agrícolas, como também na capacidade de produção de endósporos resistentes a altas temperaturas, o que garante sua permanência no local de tratamento por um período de tempo longo (VOSS, 2013).

Assim como as bactérias tem-se também os fungos entomopatogênicos, que são caracterizados como biopesticidas, pelo fato de infectarem e parasitarem insetos, porém, podem também propiciar o desenvolvimento das plantas e incrementarem a produção das culturas (MARTíNEZ-MEDINA et al., 2014; LACEY et al., 2015; BARELLI et al., 2016). Além de infectar insetos, existem diversos fungos que apresentam a capacidade de matar e digerir nematoides, sendo chamados de fungos nematófogos (NORDBRING- HERTZ et al., 2006).

Além de infectar insetos, nematóides e outros fungos, alguns deles também colonizam tecidos de plantas e podem trazer outros benefícios ao vegetal (SASAN; 
BIDOCHKA, 2012; BARELLI et al., 2016). Esses fungos são denominados de endofíticos pelo potencial de colonizar tecidos vegetais internos ao decorrer de todo ou parte do seu ciclo de vida (JABER; ENKERLI, 2016). Uma hipótese para a existência dessa associação é a de que a colonização nas raízes por fungos patogênicos de insetos foi uma adaptação como alternativa de sobrevivência para a falta de um inseto hospedeiro (HU; ST LEGER, 2002).

Para alguns fungos promotores de crescimento vegetal, há certa documentação científica da sua biologia e efeitos em insetos, pragas e plantas, como por exemplo: Beauveria bassiana, Metarhizium anisopliae, Pochonia chlamydosporia, Purpureocillium lilacinum e Trichoderma asperella (ESCUDERO et al., 2012; MARRI et al., 2016).

A colonização e estabelecimento de uma simbiose eficiente depende da adesão do fungo à superfície da planta. Um exemplo dessa necessidade de se aderir a superfície do vegetal pode ser visto no fungo Metarhizium robertsii, onde sua ligação as raízes dependem de uma adesina vegetal codificada por um gene presente em seu DNA (WANG; LEGER, 2007). Quando o fungo entra na planta, ele deve evitar o sistema de defesa dela, uma vez que ele pode causar a morte do fungo. No entanto, fungos endófitos e outros colonizadores de raízes de plantas conseguem se comunicar com a planta e estabelecer a associação (BARELLI et al., 2016).

Alguns benefícios relatados do fungo Metarhizium são a promoção do crescimento de plantas, incremento da produção primária dos sistemas agrícolas e proteção contra insetos e patógenos (BARELLI et al., 2016). Um efeito bem comum é sobre o desenvolvimento das raízes. Um aumento significativo de raízes laterais e formações de pelos radiculares foi identificado em plantas tratadas com fungos do gênero Metarhizium, quando comparado com plantas não tratadas (SASAN; BIDOCHKA, 2012).

Bactérias, vírus e fungos são alguns exemplos de microrganismos que fazem parte da história da humanidade há milênios. Plantas e microrganismos vêm interagindo e evoluindo conjuntamente há bilhões de anos. Muitas das espécies de bactérias que colaboram com o homem ajudam plantas a melhorar o crescimento de raízes, digerir nutrientes e protegê-las contra doenças, alagamentos e seca. De fato, cada centímetro quadrado de solo possui uma grande quantidade de minúsculos organismos que podem beneficiar os vegetais. E eles não estão apenas ao redor das plantas, mas em contato direto com raízes, folhas e até em órgãos e tecidos internos (HUNGRIA, 2011).

$\mathrm{Na}$ agricultura, a descoberta, o desenvolvimento e a produção de microrganismos tem sido um processo cada vez mais valioso e que vem permitindo inovações para o setor. De forma geral, as pesquisas inovadoras que estão sendo feitas nesta área podem ser sucintamente divididas em três principais etapas: Isolamento e identificação, competição e testes em campo. Um benefício adicional do uso de microrganismos na agricultura reside no fato deles poderem complementar ou até substituir outros defensivos agrícolas, além de seu uso ser considerado seguro quando comparados com outras classes de produtos agrícolas (VOSS, 2013).

O objetivo do trabalho foi verificar a eficiência de microrganismos como promotores de crescimento no desenvolvimento inicial do milho em casa de vegetação e como comparativo utilizou-se um produto comercial que atua na ativação do sistema radicular das plantas e que pode favorecer os microrganismos benéficos do solo e ampliar a interação dos mesmos com a planta. 


\section{MATERIAL E MÉTODOS}

O experimento foi conduzido em casa de vegetação localizada na Universidade Federal de Mato Grosso (UFMT), Campus Cuiabá, MT durante o mês de novembro de 2019. O solo foi coletado na cidade de Cuiabá, MT, na profundidade de $0-0,2 \mathrm{~m}$ e analisado quimicamente em um laboratório particular e as características químicas estão descritas na tabela 1.

TABELA 1. Valor do $\mathrm{pH}$, teor de nutrientes e textura do solo utilizado para o experimento em casa de vegetação, 2019.

\begin{tabular}{|c|c|c|c|c|c|c|c|c|c|c|c|c|}
\hline $\begin{array}{c}\mathrm{pH} \\
\text { (Água) }\end{array}$ & $\mathrm{P}$ & $\mathrm{K}$ & $\mathrm{Ca}+\mathrm{Mg}$ & $\mathrm{Ca}$ & $\mathrm{Mg}$ & $\mathrm{H}$ & $\mathrm{Al}$ & $\begin{array}{l}\text { Mat. } \\
\text { Org. }\end{array}$ & $\begin{array}{c}\text { Sat. } \\
\text { Bases }\end{array}$ & Areia & Silte & Argila \\
\hline & \multicolumn{2}{|c|}{$\mathrm{mg} \mathrm{dm}^{-3}$} & \multicolumn{6}{|c|}{ - } & \multicolumn{4}{|c|}{-------g Kg ${ }^{-1}-\cdots----$} \\
\hline 5,9 & 4,5 & 63,6 & 2,31 & 1,65 & 0,6 & 0,66 & 2,75 & 11,8 & 47,42 & 456 & 167 & 377 \\
\hline
\end{tabular}

Vasos de polietileno preto com capacidade de $3 \mathrm{Kg}$ foram utilizados para a condução do experimento. A semeadura foi realizada em uma mistura de areia e solo na proporção de 3:1 (P/P). Para a adubação seguiu a recomendação de (Sousa et al., 2016) e utilizou-se $2 \mathrm{~g}$ de ureia como fonte de nitrogênio; $2,5 \mathrm{~g}$ de superfosfato simples como fonte de fósforo e $2 \mathrm{~g}$ de cloreto de potássio como fonte de potássio. A umidade da mistura de areia e solo foi ajustada para $60 \%$ da capacidade de campo seguindo a Técnica do Funil, sendo necessário adicionar $150 \mathrm{~mL}$ de água/vaso.

A variedade de milho (Zea mays) utilizada foi o híbrido S1 Impacto VIP3 que estavam tratadas comercialmente com 0 fungicida Maxim Advanced (Tiabendazol+Metalaxil-M+Fludioxonil) doses recomendadas pelo fabricante e inoculadas com Azospirillum brasilense abv5 e abv6, na dose de $100 \mathrm{~mL} \mathrm{ha}^{-1}$, recomendada pelo fabricante. Foram semeadas 5 sementes de milho, porém quando essas plantas germinaram e atingiram o estágio V1 (primeira folha desenvolvida) foi realizado o desbaste, deixando apenas as duas plantas mais vigorosas.

Os tratamentos utilizados estão descritos no Quadro 1. Apenas o fungo Metarhizium anisopliae IBCB 425 foi produzido no Laboratório de Microbiologia do Solo da Universidade Federal de Mato Grosso, Campus de Cuiabá, MT. A cepa do fungo foi cedida pelo Instituto Biológico de Campinas, via processso registrado no SISGEN, número AB0E8A9. Os demais produtos foram adquiridos comercialmente.

QUADRO 1. Tratamentos utilizados no experimento de milho em casa de vegetação, 2019.

\begin{tabular}{lcccc}
\hline \multicolumn{1}{c}{ Tratamentos } & $\begin{array}{c}\text { Azospirillum } \\
\text { brasilense } \\
\text { abv5 e abv6 } \\
\left(100 \mathrm{~mL} \mathrm{ha}^{-1}\right)\end{array}$ & $\begin{array}{c}\text { Metarhizium } \\
\text { anisopliae IBCB } 425 \\
\left(0,6 \mathrm{~g} \mathrm{cova}^{-1}\right)\end{array}$ & $\begin{array}{c}\text { Rhizovator } \\
(100 \mathrm{LL} \\
\left.\text { cova }^{-1}\right)\end{array}$ & $\begin{array}{c}\text { Bacstim } \\
(0,05 \mathrm{~g}\end{array}$ \\
cova $\left.^{-1}\right)$
\end{tabular}

Os produtos utilizados foram:

a) Azospirillum brasiliense estirpes AbV5 e AbV6: bactérias fixadoras de nitrogênio atmosférico e também atuam na produção de fitormônios essenciais no 
desenvolvimento das plantas, tornando o sistema radicular mais vigoroso, auxiliando na absorção de água e de nutrientes (HUNGRIA, 2011);

b) Metarhizium anisopliae IBCB 425: fungo utilizado para o controle biológico e como promotor de crescimento, cedido ao Laboratório de Microbiologia do Solo pelo Instituto Biológico via processso no SISGEN, número de registro AB0E8A9 e mantido no laboratório para as pesquisas. A concentração do fungo $1 \times 10^{7} \mathrm{~g}^{-1}$.

c) Rhizovator: produto comercial Omnia desenvolvido pelo Laboratório de Biologia do solo da Omnia Nutriology (OMNIBIO), atua na ativação do sistema radicular, favorecendo os microrganismos benéficos do solo e ampliando a diversidade microbiana e sua interação com a planta.

d) Bacstim: produto comercial desenvolvido pela Omnia Nutriology (OMNIBIO) à base de Bacillus sp altamente benéficos às plantas, estão presentes na zona radicular, tendo como objetivo melhorar a mineralização e a absorção de nutrientes e produzir fitormônios incentivando o crescimento das plantas. Este gênero tem a capacidade de formar esporos quando em situações adversas, garantindo a perpetuação da espécie.

Durante o período de desenvolvimento do experimento, a temperatura e umidade foram controladas, sendo a temperatura mantida a $28^{\circ} \mathrm{C}$. A umidade dos vasos foi mantida em $60 \%$ da capacidade de campo e feita manualmente todos os dias. Os parâmetros avaliados foram massa fresca da parte aérea; massa fresca da raiz; massa seca da parte aérea massa seca da raiz; comprimento da parte aérea; número de folhas; comprimento das duas últimas folhas expandidas.

O delineamento experimental foi inteiramente casualizado (DIC) com 5 tratamentos e 4 repetições. Os resultados obtidos foram submetidos à análise de variância e as médias comparadas pelo teste de Scott-Knott, a 5\% de probabilidade. As análises estatísticas foram processadas por meio de software Sisvar versão 5.6 (FERREIRA, 2019).

\section{RESULTADOS E DISCUSSÃO}

As médias das variáveis peso de massa fresca da parte aérea (MFPA), peso de massa fresca da raiz (MFR), peso de massa seca da parte aérea (MSPA) e peso de massa seca da raiz (MSR) do milho estão descritos na tabela 2.

TABELA 2. Massa fresca da parte aérea (MFPA) e da raiz (MFR); massa seca da parte aérea (MSPA) e da raiz (MSR) de milho em submetidos à diferentes, 2019.

\begin{tabular}{lcccc}
\multicolumn{1}{c}{ Tratamentos } & MFPA & MFR & MSPA & MSR \\
\hline T1: Azospirillum brasiliense & $7,7 \mathrm{c}$ & $3,1 \mathrm{~d}$ & $1,0 \mathrm{c}$ & $0,4 \mathrm{c}$ \\
T2: Azospirillum brasiliense + & $4,8 \mathrm{C}$ & $1,1 \mathrm{e}$ & $0,8 \mathrm{c}$ & $0,2 \mathrm{c}$ \\
Metarhizium anisopliae IBCB 425 & $28,2 \mathrm{a}$ & $25,2 \mathrm{a}$ & $3,8 \mathrm{a}$ & $2,1 \mathrm{a}$ \\
T3: Azospirillum brasiliense + Rhizovator & $11,8 \mathrm{~b}$ & $10,6 \mathrm{c}$ & $1,6 \mathrm{~b}$ & $0,8 \mathrm{~b}$ \\
T4: Azospirillum brasiliense + Metarhizium & $14,5 \mathrm{~b}$ & $15,6 \mathrm{~b}$ & $1,8 \mathrm{~b}$ & $1,1 \mathrm{~b}$ \\
anisopliae IBCB 425+ Rhizovator & 13,4 & 11,1 & 1,8 & 0,92 \\
T5: Azospirillum brasiliense + Bacstim & 19,07 & 8,8 & 20,2 & 21,6 \\
\hline Média & & &
\end{tabular}

* Os valores seguidos da mesma letra na coluna não diferem entre si de acordo com o teste de Scott-Knott $(p<0,05)$ 
Verificou-se que o uso do produto comercial Rhizovator proporcionou aumento em todos os parâmetros avaliados, comprovando então sua eficiência em atuar no desenvolvimento da planta devido a maior absorção de nutrientes por meio da ação dos microrganismos já existentes na rizosfera. Entre os tratamentos $M$. anisopliae IBCB 425 + Rhizovator e Bacstim, não houve diferenças estatísticas significativas para peso de massa fresca da parte aérea, bem como entre testemunha e $M$. anisopliae. Para o parâmetro peso de massa fresca da raiz, houve diferença estatística significativa entre todos os tratamentos, onde obteve-se uma média geral de $11,1 \mathrm{~g}$ por planta (Tabela 2).

Segundo o experimento de Mazzuchelli (2014), e colaboradores em que testaram a inoculação do Bacillus subitilis na cultura do milho, o mesmo tem uma resposta positiva à inoculação de $B$. subtilis no sulco de plantio em relação ao peso da massa fresca da parte aérea, o que pode ser confirmado no presente trabalho, quando o resultado do tratamento com Bacstim trouxe o segundo maior peso de massa fresca da parte aérea do milho.

Para os parâmetros massa seca da parte aérea e da raiz, não houveram diferenças estatísticas significativas entre os tratamentos $M$. anisopliae IBCB 425+ Rhizovator e Bacstim, obtendo-se as segundas melhores médias e para a testemunha e o tratamento $M$. anisopliae também não houveram diferenças estatísticas entre eles (Tabela 3).

Chagas et al. (2017), em trabalho avaliando a inoculação e coinoculação de Bacillus subtilis e Trichoderma asperellum em sementes de soja, feijão-caupi, milho e arroz, observou que aos 20 dias após a emergência (DAE) obteve-se maior peso de massa seca da parte aérea e massa seca total quando as sementes de milho foram submetidas à inoculação com $B$. subtilis e coinoculação com $T$. asperellum.

Para o parâmetro comprimento de parte aérea observou-se diferenças estatísticas significativas entre os tratamentos Rhizovactor, Bacstim e M. anisopliae IBCB 425 + Rhizovator, destacando-se com a maior média o tratamento Rhizovator, com $18,05 \mathrm{~cm}$. Já entre a testemunha, o tratamento $M$. anisopliae IBCB 425 e $M$. anisopliae IBCB 425 + Rhizovator, não se diferiram entre si. Quanto ao número de folhas, não houveram diferenças estatísticas significativas, sendo a média de 3,2 folhas por planta (Tabela 3).

TABELA 3. Comprimento da parte aérea (PA), número de folhas e comprimento das duas últimas folhas expandidas de milho, experimento casa de vegetação, 2019.

\begin{tabular}{lccc}
\hline \multicolumn{1}{c}{ Tratamentos } & $\begin{array}{c}\text { Comprimento PA } \\
\text { (cm) }\end{array}$ & $\begin{array}{c}\text { Número de } \\
\text { folhas }\end{array}$ & $\begin{array}{c}\text { Comprimento 2 últimas } \\
\text { folhas expandidas }(\mathrm{cm})\end{array}$ \\
\hline T1: A. brasiliense & $11,9 \mathrm{c}$ & $3,2 \mathrm{a}$ & $26,2 \mathrm{~b}$ \\
T2: $\boldsymbol{A}$. brasiliense + M. anisopliae & $9,5 \mathrm{c}$ & $2,7 \mathrm{a}$ & $24,4 \mathrm{~b}$ \\
IBCB 425 & $18,1 \mathrm{a}$ & $4,0 \mathrm{a}$ & $30,7 \mathrm{a}$ \\
T3: $\boldsymbol{A}$. brasiliense + Rhizovator & & & \\
T4: $\boldsymbol{A}$. brasiliense + M. anisopliae & $12,8 \mathrm{C}$ & $3,2 \mathrm{a}$ & $24,5 \mathrm{~b}$ \\
IBCB 425+ Rhizovator & $14,4 \mathrm{~b}$ & $4,0 \mathrm{a}$ & $25,8 \mathrm{~b}$ \\
T5: $\boldsymbol{A}$. brasiliense + Bacstim & 13,3 & 3,4 & 26,7 \\
\hline Média & 13,1 & 22,8 & 22,5 \\
CV $(\%)$ &
\end{tabular}

${ }^{*}$ Os valores seguidos da mesma letra na coluna não diferem entre si de acordo com o teste de ScottKnott $(p<0,05)$

Sousa et al. (2016) avaliaram as plântulas de milho em solução nutritiva sob ação de bioestimulantes à base de microrganismos e obteve resultados que comprovaram o efeito benéfico dos microrganismos ao desenvolvimento do milho, $\mathrm{e}$ 
nesse estudo, os autores puderam observar que as plântulas que ficaram na solução nutritiva que continha a cepa de Rizosférica Bacillus B1 e Azospirillum E1 reduziram significativamente a área da superfície de raízes grossas (diâmetro maior que 2 $\mathrm{mm})$.

O tratamento com Azospirillum E1 e Bacillus B1 proporcionou um aumento significativo de raízes finas (diâmetro entre 1 e $2 \mathrm{~mm}$ ) e do peso seco da parte aérea. $O$ aumento de raízes finas e redução de raízes grossas tende a aumentar a aquisição de nutrientes, especialmente fósforo (SOUSA et al., 2016).

Para o parâmetro comprimento das duas últimas folhas expandidas, o tratamento $A$. brasiliense + Rhizovator foi o único que diferiu em relação aos demais tratamentos. Pedrinho et al. (2010) identificaram e avaliaram rizobactérias isoladas de raízes de milho e constataram que o isolado de Sphingomonas spp proporcionou maior crescimento da parte aérea da planta de milho em comparação à outras bactérias isoladas e esse isolado pode se tornar um microrganismo promissor como promotora de crescimento de plantas quando comparados ao Azospirillum brasiliense que é o mais utilizado na cultura do milho para promoção de crescimento. Os resultados obtidos no presente estudo corroboram com os resultados obtidos por Pedrinho e colaboradores (2010), cujo comprimento da parte aérea foi diferente entre todos os tratamentos, ou seja, os microrganismos se comportam de maneiras diferentes na promoção de crescimento de planta.

\section{CONCLUSÃO}

Para as condições em que o trabalho foi desenvolvido os microrganismos utilizados não desempenharam o papel como promotores de crescimento e não houve o desenvolvimento inicial do milho em função da aplicação dos mesmos.

O produto comercial Rhizovator, utilizado na ativação do sistema radicular das plantas foi benéfico e promoveu desenvolvimento inicial da cultura do milho em casa de vegetação.

\section{REFERÊNCIAS}

BARELLI, L.; MOONJELY, S.; BEHIE, S. W.; BIDOCHKA, M. J. Fungi with multifunctional lifestyles: endophytic insect pathogenic fungi. Plant Molecular Biology, v. 90, n. 6, p. 657-664, 2016. Disponível em: < https://link.springer.com/content/pdf/10.1007/s11103-015-0413-z.pdf >. doi: 10.1007/s11103-015-0413-z

CHAGAS, L. F. B.; MARTINS, A. L. L.; CARVALHO FILHO, M. R.; MILLER, L. O.; OLIVEIRA, J. C. et al. Bacillus subtilis e Trichoderma sp. no incremento da biomassa em plantas de soja, feijão-caupi, milho e arroz. Revista AgriEnvironmental Sciences, v. 3, n. 2, 2017. Disponível em: < https://revista.unitins.br/index.php/agri-environmental-sciences/index>.

ESCUDERO, N.; LOPEZ-LLORCA, L. V. Effects on plant growth and root-knot nematode infection of an endophytic GFP transformant of the nematophagous fungus Pochonia chlamydosporia. Symbiosis, v. 57, n. 1, p. 33-42, 2012. Disponível em: $\quad<\quad$ https://imem.ua.es/en/documentos/imem-files/researcharticles/traduciendo/escudero-y-lopez-llorca-symbiosis-2012.pdf >. doi: 10.1007/s13199-012-0173-3 
FERREIRA, D. F. SISVAR: A computer analysis system to fixed effects split plot type desings. Revista Brasileira de Biometria, v. 37, n. 4, p. 529-535, 2019. Disponível em: < http://www.biometria.ufla.br/index.php/BBJ/article/view/450 >. doi: $10.28951 / \mathrm{rbb} . \mathrm{v} 37 \mathrm{i} 4.450>$.

HU, G.; ST. LEGER, R. J. Field studies using a recombinant mycoinsecticide (Metarhizium anisopliae) reveal that it is rhizosphere competent. Revista Applied Environmental Microbiology, v. 68, n. 12, p. 6.383-6.387, 2002. Disponível em: $<$ https://www.ncbi.nlm.nih.gov/pmc/articles/PMC134390/pdf/0593.pdf>.

doi: 10.1128/AEM.68.12.6383-6387.2002

HUNGRIA, M. Inoculação com Azospirillum brasiliense: inovação em rendimento a baixo custo. Folhetos Embrapa Soja, 36p, 2011. Disponível em: < https://www.embrapa.br/busca-de-publicacoes/-/publicacao/879471/inoculacao-comazospirillum-brasilense-inovacao-em-rendimento-a-baixo-custo >.

JABER, L. R.; ENKERLI, J. Effect of seed treatment duration on growth and colonization of Vicia faba by endophytic Beauveria bassiana and Metarhizium brunneum. Revista Biological Control, v. 103, p. 187-195, 2016. Disponível em: < https://www.sciencedirect.com/science/article/abs/pii/S1049964416301761?via\%3Di hub >. doi: 10.1016/j.biocontrol.2016.09.008

JUNG, S. C.; MARTINEZ-MEDINA, A.; LOPEZ-RAEZ, J. A.; POZO, M. J. Mycorrhiza-induced resistance and priming of plant defenses. Revista Journal of Chemical Ecology, v. 38, n. 6, p. 651-664, 2012. Disponível em: < https://link.springer.com/article/10.1007/s10886-012-0134-6 >. doi: 10.1007/s10886012-0134-6

LACEY, L. A.; GRZYWACZ, D.; SHAPIRO-ILAN, D. I.; FRUTOS, R.; BROWNBRIDGE, M. et al. Insect pathogens as biological control agents: back to the future. Revista Journal of Invertebrate Pathology, v. 132, p. 1-41, 2015. Disponível em:

https://www.sciencedirect.com/science/article/abs/pii/S0022201115001342?via\%3Di hub >. doi: 10.1016/j.jip.2015.07.009

LIAO, X.; LU, H. L.; FANG, W.; LEGER, R. J. ST. Overexpression of a Metarhizium robertsii HSP25 gene increases thermotolerance and survival in soil. Revista Applied Microbiology and Biotechnology, v. 98, n. 2, p. 777-783, 2014. Disponível em: < https://link.springer.com/article/10.1007\%2Fs00253-013-5360-5 >. doi: $10.1007 / \mathrm{s} 00253-013-5360-5$

MARRI, D.; GOMEZ D. A. M. A.; WILSON, D.; BILLAH, M.K.; YEBOAH, S. et al. Evaluation of the efficacy of a commercial formulation of Beauveria bassiana for the control of the invasive fruit fly Bactrocera dorsalis (Diptera: Tephritidae). Revista Biopesticides International, v. 12, n. 1, p. 9-18, 2016. Disponível em: < https://www.researchgate.net/publication/309769606_Evaluation_of_the_efficacy_of_ a_commercial_formulation_of_beauveria_bassiana_for_the_control_of_the_invasive _fruit_fly_bactrocera_dorsalis_Diptera_Tephritidae $>$. 
MARTíNEZ-MEDINA, A.; ALGUACIL, M. D. M.; PASCUAL, J. A. ; VAN WEES, S. C. $M$. et al. Phytohormone Profiles induced by Trichoderma isolates correspond with their biocontrol and plant growth-promoting activity on melon plants. Revista Journal of Chemical Ecology, v. 40, n. 7, p. 804-815, 2014. Disponível em: < https://link.springer.com/article/10.1007/s10886-014-0478-1 >. doi: 10.1007/s10886014-0478-1

MAZZUCHELLI, R. C. L.; SOSSAI, B. F.; ARAUJO, F. F. Inoculação de Bacillus subtilis e Azospirillum brasilense na cultura do milho. Revista Colloquium Agrariae, v. 10, n.2, p.40-47, 2014. Disponível em: < http://revistas.unoeste.br/index.php/ca/article/view/1151/1204 >. doi: 10.5747/ca.2014.v10.n2.a106

NORDBRING-HERTZ, B.; JANSSON, H. B.; TUNLID, A. Nematophagous fungi. Encyclopedia of Life Sciences, p. 1-11, 2006. Disponível em: < https://onlinelibrary.wiley.com/doi/abs/10.1038/npg.els.0004293 >. doi: 10.1038/npg.els.0004293

OGGERIN, M.; TORNOS, F.; RODRÍGUEZ, N.; MORAL, C.; SÁNCHEZ-ROMÁN, M.; et al. Specific jarosite biomineralization by Purpureocillium lilacinum, an acidophilic fungi isolated from Río Tinto. Revista Environmental Microbiology, v. 15, n. 8, p. 2228-2237, 2013. Disponível em: < https://sfamjournals.onlinelibrary.wiley.com/doi/abs/10.1111/1462-2920.12094 >. doi: $10.1111 / 1462-2920.12094$

PEDRINHO, E. A. N.; GALDIANO JUNIOR, R. F. G.; CAMPANHARO, J.C.; ALVES, L.M.C.; LEMOS, E. G. M. de. Identificação e avaliação de Rizobactérias isoladas de raízes de Milho. Revista Bragantia, v. 69, n. 4, p. 905-911, 2010. Disponível em: < https://www.scielo.br/scielo.php?script=sci_arttext\&pid=S0006-

$87052010000400017 \&$ Ing=pt\&tlng=pt >. doi: $10.1590 /$ S0006-87052010000400017

SASAN, R. K.; BIDOCHKA, M. J. The insect-pathogenic fungus Metarhizium robertsii (Clavicipitaceae) is also an endophyte that stimulates plant root development. Revista American journal of botany, v. 99, n. 1, p. 101-107, 2012. Disponível em: $<$ https://bsapubs.onlinelibrary.wiley.com/doi/full/10.3732/ajb.1100136 >. doi: 10.3732/ajb.1100136

SINGH, J. S.; PANDEY, V. C.; SINGH, D. P. Efficient soil microorganisms: A new dimension for sustainable agriculture and environmental development, Revista Agriculture, Ecosystems \& Environment, v. 140, (3-4), p. 339-353, 2011. Disponível em: https://www.sciencedirect.com/science/article/abs/pii/S0167880911000351?via\%3Di hub >. doi: 10.1016/j.agee.2011.01.017

SOUSA, S. M.; OLIVEIRA, C. A.; GOMES, E. A.; LANA, U. G. P.; SANTOS, N. G.; et al. Avaliação de plântulas de milho em solução nutritiva sob a ação de bioestimulantes à base de microrganismos. Embrapa Milho e Sorgo - Sete Lagoas, MG. XXXI Congresso Nacional de Milho e Sorgo - Bento Gonçalves - 25 a 29 de setembro de 2016. Disponível em: < https://www.embrapa.br/milho-e- 
sorgo/busca-de-publicacoes/-/publicacao/1054133/avaliacao-de-plantulas-de-milhoem-solucao-nutritiva-sob-a-acao-de-bioestimulantes-a-base-de-microrganismos >.

VOSS, G. B. Produção de Bacillus subtilis em biorreatores airlift e sua aplicação no controle de nematoide de galhas do tomateiro. Dissertação (Mestrado em Engenharia de Alimentos) - Universidade Federal de Santa Catarina, Centro Tecnológico. Programa de Pós-Graduação em Engenharia de Alimentos. Florianópolis, $\mathrm{SC}$, 2013. $115 p$.

Disponível em: https://repositorio.ufsc.br/handle/123456789/106979>.

WANG, C.; LEGER, R. J. The MAD1 adhesin of Metarhizium anisopliae links adhesion with blastospore production and virulence to insects, and the MAD2 adhesin enables attachment to plants. Revista Eukaryotic cell, v. 6, n. 5, p. 808816, 2007. Disponível em: < https://ec.asm.org/content $/ 6 / 5 / 808$ >. doi: 10.1128/EC.00409-06 